Military Technical College Kobry El-Kobbah, Cairo, Egypt

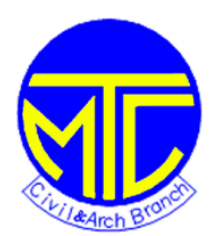

\title{
Behavior of Pre-Stressed Concrete Flat-Slabs in The Punching Failure
}

$$
\text { By }
$$
M. Abou Zeid Tarkhan*
N. H. Abdel Motaal**
E. M. El-Tehewy***

Ali N. Deeb****

\section{Abstract:}

The phenomenon of the punching failure of reinforced concrete slabs and the effect of the pre-stressing on the failure mechanism has been investigated in this paper. This paper deals with the behavior of pre-stressed concrete slabs, subjected to symmetrically static loading. A numerical model based on the finite element method using the computer program "ANSYS" (version 11).

Sixteen pre-stressed flat slabs and one conventional flat slab has been analyzed. All the slabs represent an interior slab-column connection. The slabs have dimensions $900 \times 900 \times 80 \mathrm{~mm}$, with interior square column 132x132 $\mathrm{mm}$. The main objective of this research is to study the effect of pre-stressing force and its distribution along the crosssection of slab on the punching failure.

\section{Keywords:}

Slab-column connection, Punching shear, Finite-element analysis, Flat slab, Pre-stressed concrete

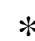

ASS Prof. Dr., Helwan University, Cairo, Egypt

Dr., Lecturer, Military Technical College, Cairo, Egypt

Dr., Lecturer, Military Technical College, Cairo, Egypt

M.SC. Student, Civil Engineering Department, MTC, Cairo, Egypt 


\section{Introduction:}

Flat reinforced concrete slabs are widely used in practice. Flat slab construction in multi-storey structures offers advantages in terms of economy and reduces storey height. A slab-column connection in flat slab construction, however, frequently subjected to a combination of high bending moments and high shear stresses, which can produce punching shear failure.

Common failure of such slabs is by punching of the supporting column through the slab. The problem with this failure mode is being brittle and catastrophic due to the inability of the concrete to support the large stresses that are developed. The failure surface is similar to that of a truncated cone or a pyramid around the column. The failure surface extends from the bottom of the slab, at the support, diagonally upward to the top surface. The angle of inclination with the horizontal face depends on the slab dimensions and amount of reinforcement in it. Then it is obvious, that in design, attention should be given to both strength and ductility when punching shear being considered [1].

The finite-element technique, introduced in the 1950's, has become the most widely accepted numerical technique in the engineering analysis. However, it was not until the 1960's that researchers began to use this technique as aid in the analysis of the concrete structures. Although there are much works carried out in this area, this technique has not been generally adopted in design, Due to the great availability amount of experimental data on punching shear failure of the slabs [1]. The work, presented in this paper, focuses on the numerical model developed to predict the response of the slab including the load-deflection behavior, the first cracks, and the ultimate failure load. Threedimensional non-linear finite-element models were created to simulate the behavior of the flat slab by using the program "ANSYS" [2].

The current work presents the numerical analysis research carried out to study the behavior of pre-stressed concrete flat slabs in punching. Effect of number of tendons in slab and the pre-stressing force on the punching shear capacity of interior slab-column connection are studied.

\section{Finite element models:}

Extensive use of the finite-element method for the numerical modeling of punching shear failure mode is carried out. In this study, it is decided to focus on modeling both the load-deflection characteristics of the slabs and the initial onset of cracking. The experimental data obtained from the proven study [1,3] are used as a comparison with the numerical results. The finite-element analysis package "ANSYS" (version 11) used to develop numerical models. The three dimensional element is used to represent the structure. 


\subsection{Finite element model of concrete:}

The three-dimensional 8-node brick element (Solid 65 reinforced concrete solids) used for modeling the concrete. The element has eight corner nodes, and each node has three degree of freedom, (translation in the $\mathrm{X}, \mathrm{Y}$ and $\mathrm{Z}$ direction). The concrete is assumed homogeneous and initially isotropic [2]. The compressive uniaxial stress-strain relationship for concrete model are obtained by using the following equations to compute the multi-linear isotropic stress-strain curve for the concrete [4] as shown in Fig. 1.

$$
\begin{array}{lll}
f_{o}=\varepsilon E & \text { For } & 0 \leq \varepsilon \leq \varepsilon_{1} \\
f_{o}=\frac{\varepsilon E}{1+\left(\frac{\varepsilon}{\varepsilon_{0}}\right)^{2}} & \text { For } & \varepsilon_{1} \leq \varepsilon \leq \varepsilon_{0} \\
f_{o}=f_{o}^{v} & \text { For } & \varepsilon_{0} \leq \varepsilon \leq \varepsilon_{u} \\
\varepsilon_{0}=\frac{2 f_{0}}{E} & , & \varepsilon_{1} \text { at } 0.3 f_{o}^{\prime}
\end{array}
$$

Where:

$f_{c}:$ Stress at any strain $\varepsilon . N / \mathrm{mm}^{2}$.

$f_{c}^{I}$ : Characteristic compressive strength of cylinder at 28 days for concrete. $\mathrm{N} / \mathrm{mm}^{2}$. $\varepsilon_{0}:$ Strain at the ultimate compressive strength. $f_{c}^{I}$.

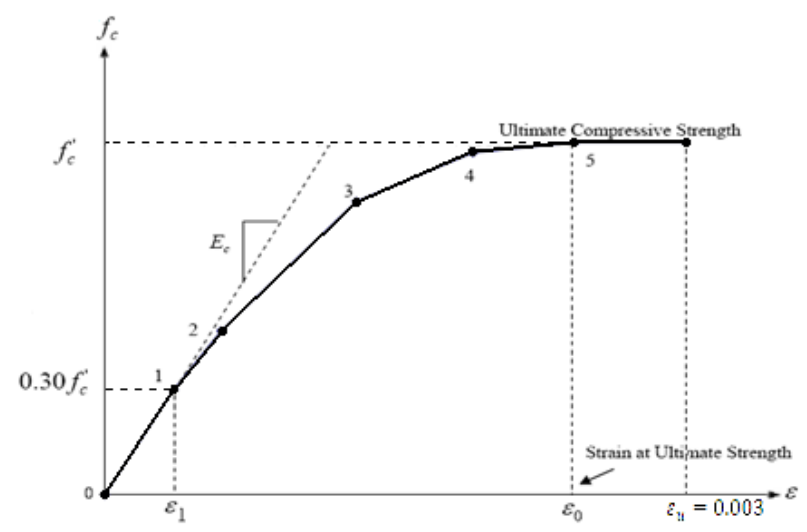

Fig (1): Simplified compressive uniaxial stress- strain curve of concrete [4]

The element includes a smeared crack analogy for cracking in tension zones and a plasticity algorithm to account for the possibility of concrete crushing in compression zones. Each element has eight integration points at which cracking and crushing can be checked [5]. 


\subsection{Finite element model of reinforcement:}

In this study, the discrete representation used to model the steel reinforcements by using the (3D spar Link8 element). The reinforcement in the discrete model uses bar or beam elements that are connected to concrete mesh nodes, [6]. The stress-strain relationship for ordinary reinforcing steel is a bilinear relationship assumed elasticperfectly plastic as shown in Fig. 2. $\left(f_{y}=460 \mathrm{MPa}\right)$.

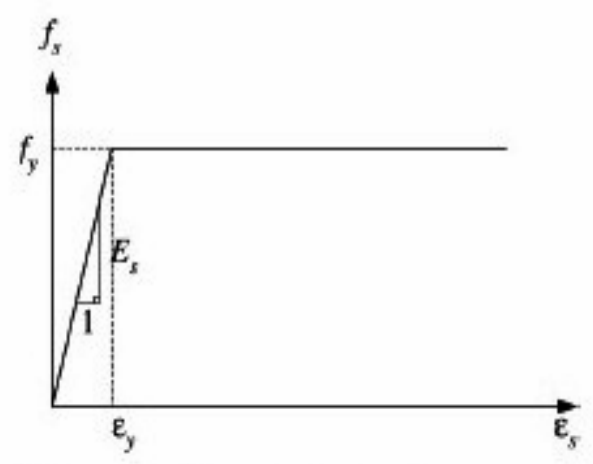

Fig (2): Constitutive law for steel reinforcement [6]

\subsection{Finite element model of pre-stressed tendon:}

The pre-stress in finite element applied as real pre-stress to the tendon with initial conditions. The pre-stressing stress was taken as the initial value, equal to the effective stress, and appears in the analysis as initial strain in link element, [6].

For pre-stressing tendons, bilinear elastic-plastic with hardening is the relationship of stress-strain, as shown in Fig. 3. $\left(\sigma_{p y}=1625 \mathrm{MPa}, \varepsilon_{p y}=0.00979\right)$.

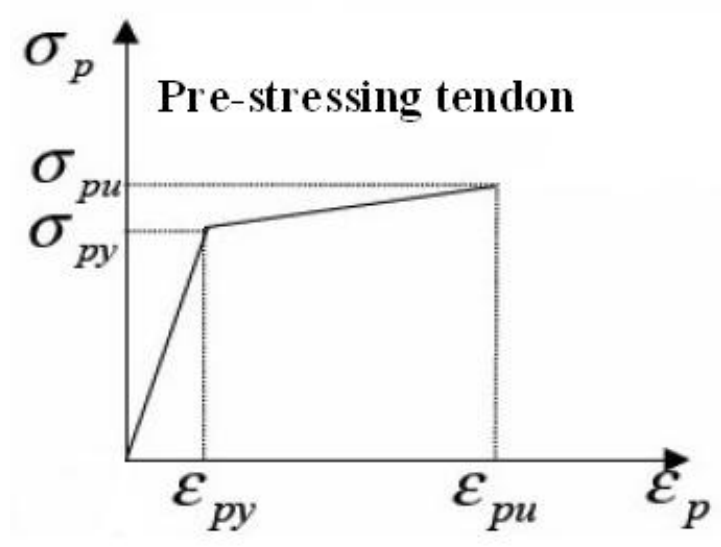

Fig (3): Constitutive law for pre-stressing steel [6] 


\subsection{Finite element model of anchorages steel plates:}

The tendons connected to a steel plate at the anchorage zone. In addition, steel plates added at the loading location to avoid stress concentration problems. The solid element (solid 45) was used to represent the steel plates. The element defined with 8-nodes and at each node three degrees of freedom, (translations in $\mathrm{X}, \mathrm{Y}$, and $\mathrm{Z}$ directions).

\subsection{Analytical Model:}

In this study, sixteen specimens are presented to investigate the behavior of prestressed flat slabs by developing a general analytical approach to predict the ultimate punching response, taking into consideration the effect of pre-stressing force. The accuracy and validity of the finite element models are determined by analyzing one slab S1 with the same data of the slab tested in Ref. [1]. All the slabs have dimensions 900x900x80 mm, with interior square column 132x132 $\mathrm{mm}$. The ordinary bonded steel bars (up and bottom reinforcement) represent $\mu=1 \%$ of concrete cross-section having yield strengths of $460 \mathrm{~N} / \mathrm{mm}^{2}$. The pre-stressing steel of area $37.5 \mathrm{~mm}^{2}$ is used. The yield strength, ultimate strength, yield strain, and modulus of elasticity were 1625, 1834, 0.00979 , and $200898 \mathrm{~N} / \mathrm{mm}^{2}$ respectively. The reinforcement and pre-stressing steel of the analytical specimen are show in Fig. 4.

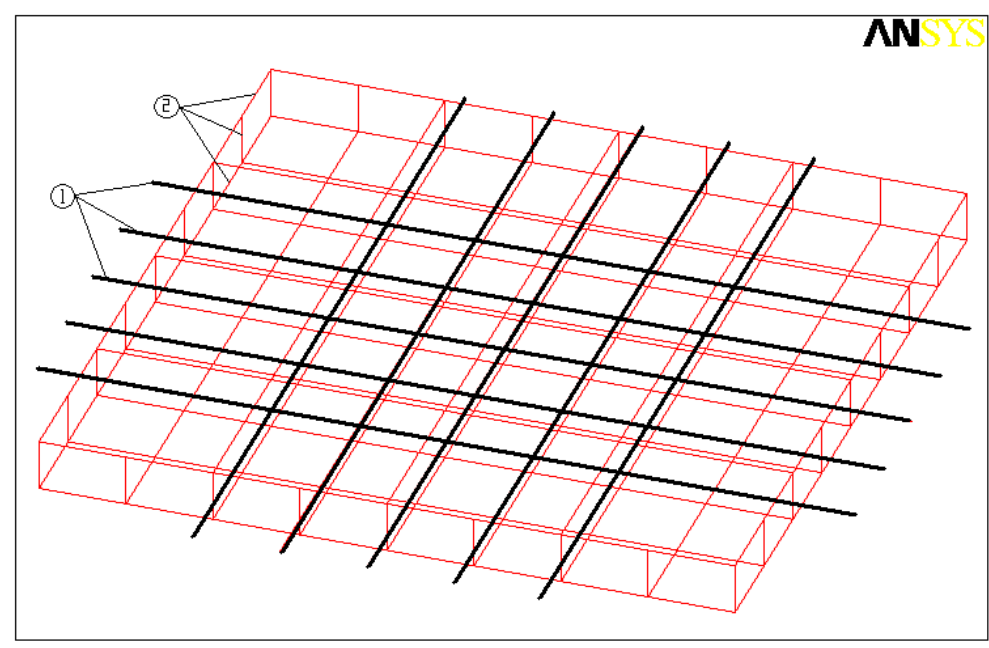

Fig (4): Reinforcement and pre-stressing steel (1) Pre-stressing steel, (2) Reinforcement steel

The focus of these analyses is to model the load-deflection behavior of the specimen S1.

The numerical models developed in two different groups. These groups consisted of models developed for S3, S5 slabs, Fig. 5. 


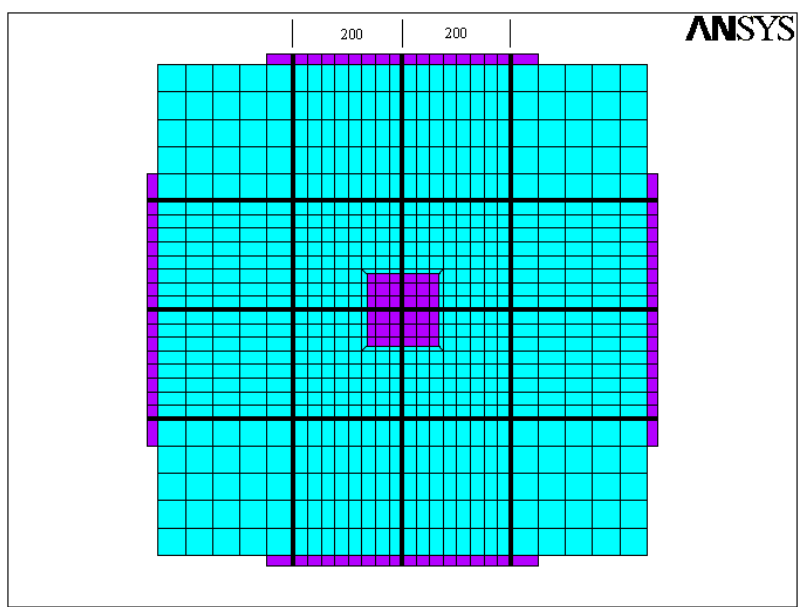

S3

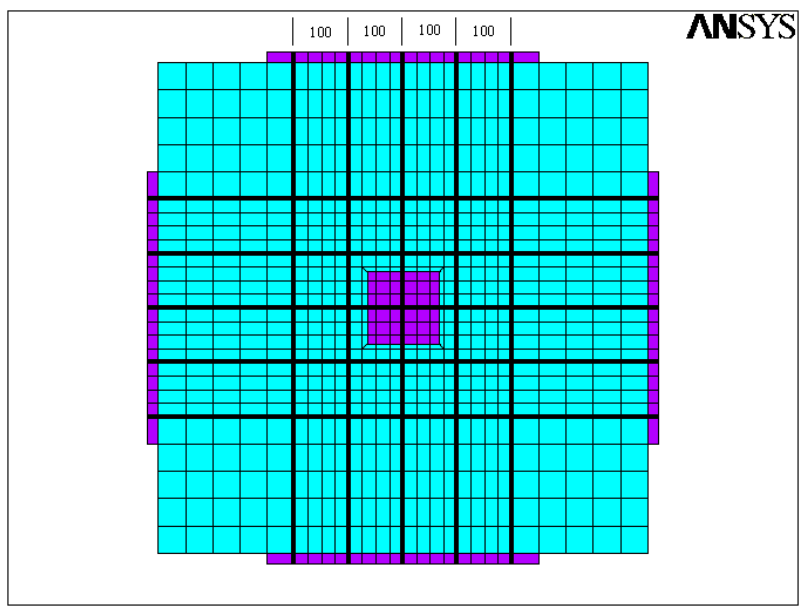

S5

Fig (5): Pre-stressing tendons in slabs, (three and five tendons)

Group S3 which has three rectilinear tendons with eccentricity from center of slab depth $10 \mathrm{~mm}$ and spacing between tendons $200 \mathrm{~mm}$ in each direction, having a total prestressing force of 15, 30,60, 90, 120, 150, 180, and $210 \mathrm{KN}$, respectively. While group S5 has five rectilinear tendons with eccentricity from center of slab depth $10 \mathrm{~mm}$ and spacing between tendons $100 \mathrm{~mm}$ in each direction and the same total of pre-stressing force. The vertical load applied centrally through the column stub, with the slab specimen simply supported along four edges to simulate an inverted isolated slabcolumn connection. The load applied monotonically with intervals $5 \mathrm{KN}$. Readings has taken at $5 K N$ intervals, Fig. 6.

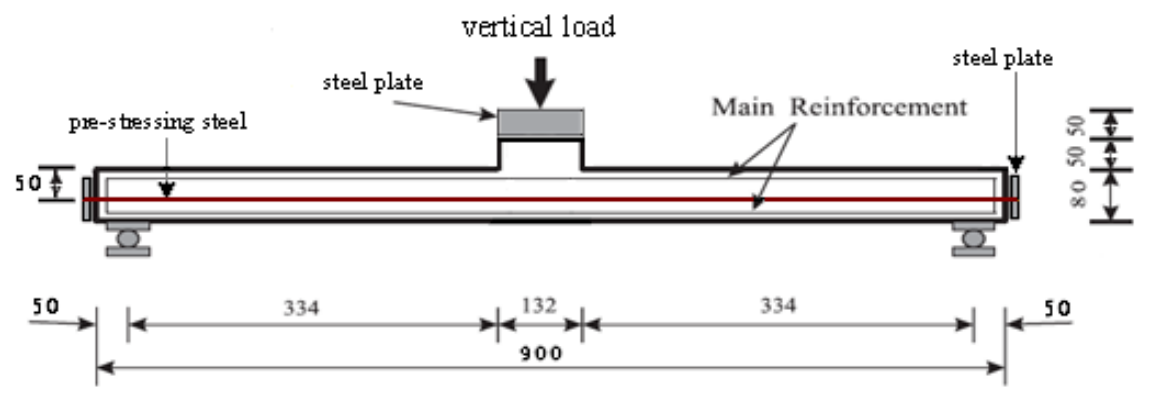

Fig (6): Implementing vertical load and supporting system [1]

This study carried out to look at the effect of pre-stressing force on the punching behavior of the slabs. It is possible to establish the relationship between the prestressing force and the number of tendons. The typical dimensions of the finite element specimen are show in Fig. 7. The mesh layout used in the present models was the same in all analytical models. The density of the mesh has increased under the area of loading 
and reduced towards the edges of the slab. Therefore, the mesh was not uniform. Using a single layer of under integrated elements to represent the depth of the slab is obviously incorrect; therefore, to demonstrate the improvement in accuracy, and to look at the effect of the pre-stressing force on the behavior of the slab, five elements was used to represent the depth of the slab.

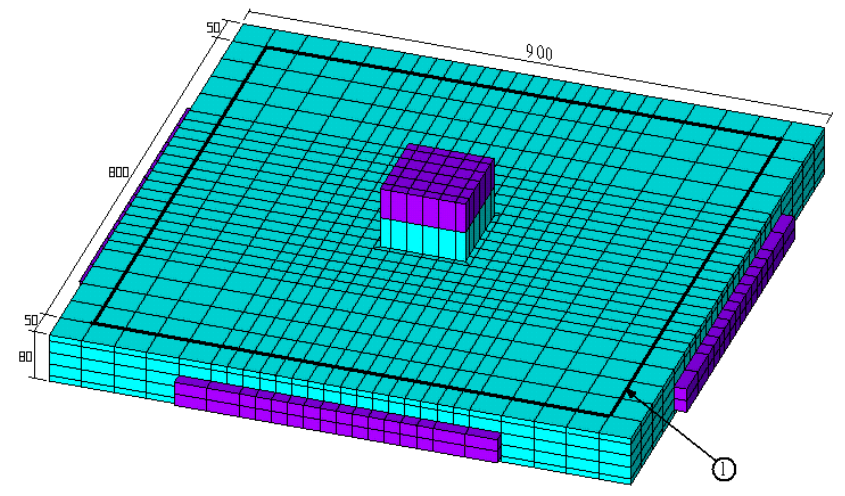

Fig (7): Numerical model representation of experimental specimens, (1) Line along which slab supported on bottom surface

The objective of this research is to study the effect of pre-stressing force and its distribution along the cross-section of slab on the punching failure. The parameters, which are studied in this research, are:

1- Pre-stressing force in slab. 2- Number of tendons in specimens.

\section{Results of load-deflection analyses:}

The vertical load versus the slab deflection of the analytical model has plotted and compared with that in the experimental model, as shown in Fig. 8. It is clear that the failure mode of the analytical model is similar to that of experimental model, and behaves in the same manner. It is also clear from the figure that the analytical results are approximately near the experimental results with the same load of failure. The difference between them ranges between 10-20\%, which means that the analytical results are reasonable.

Inspecting the curve in Fig. 9 at the first stage, the curve indicates small deflection under increasing load values represented by straight-line (region I). After the curves shows a plastic behavior (region II) which begins after the first crack load. Finally, (region III) the deflection is greatly increased with slight increase the load. The reason of failure load has not fixed in every slab, but one can say that the failure is due to one of the following: flexural, compression or punching. The failure point is determined by the analytical model at the load where the computer program indicating no deflection. 


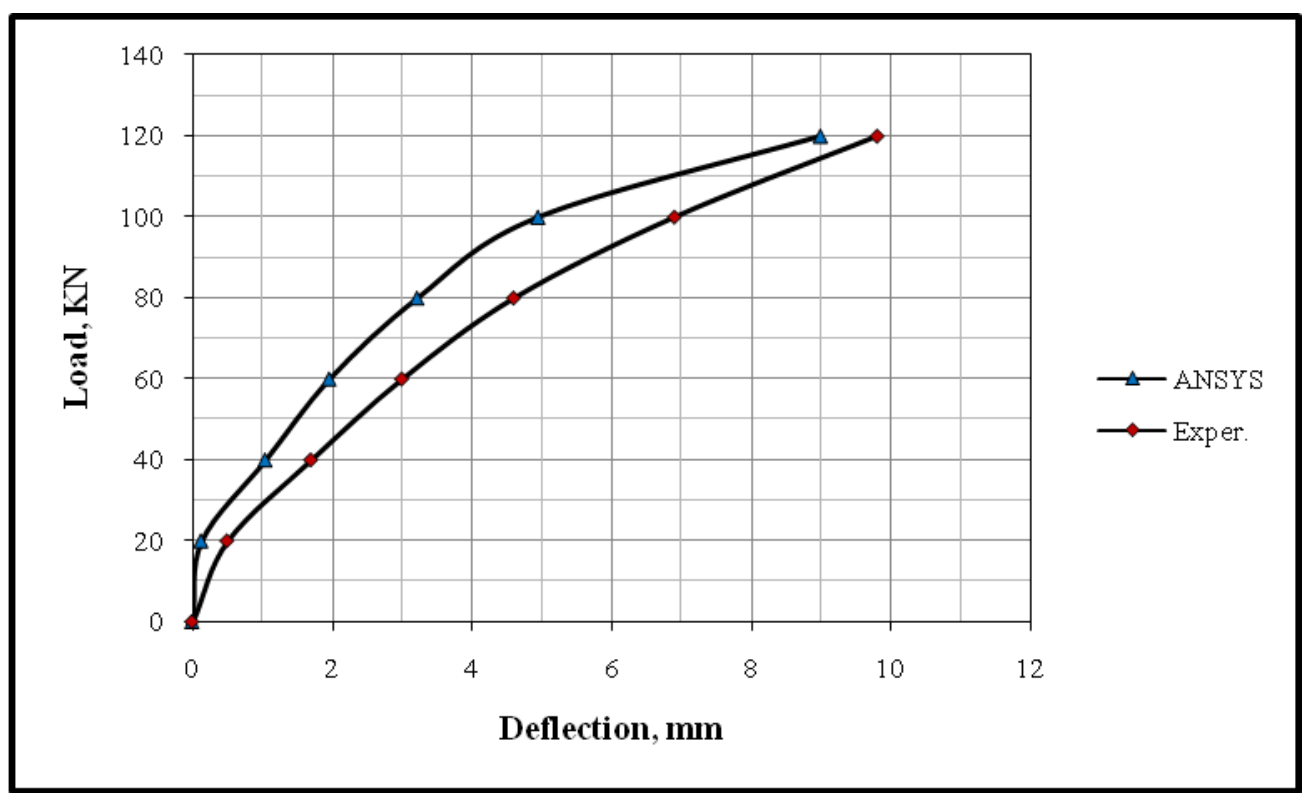

Fig (8): Load-deflection curve of both analytical and experimental specimen

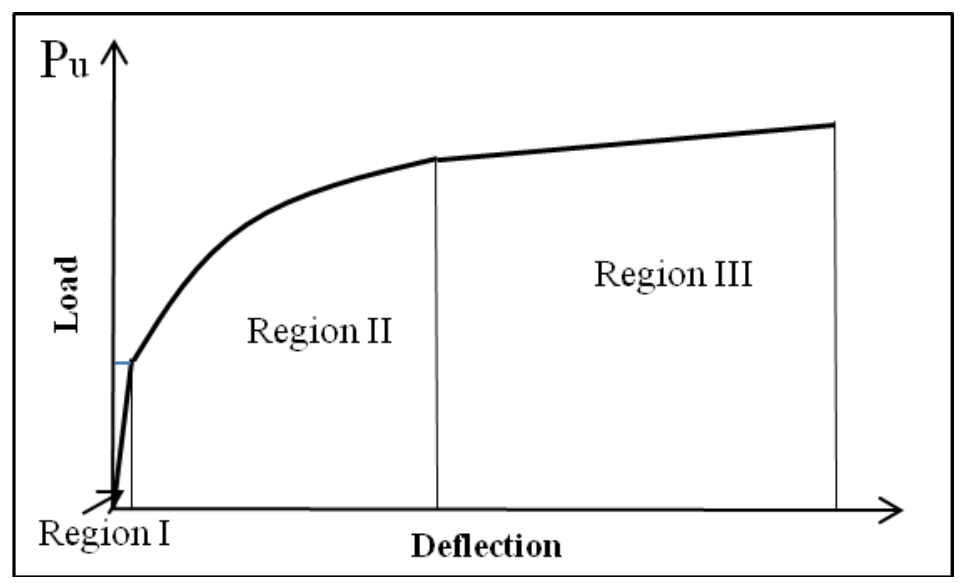

Fig (9): Different regions of load-deflection curve

\subsection{Effect of pre-stressing force:}

Looking on the curves at Fig. 10 of the numerical models slabs S3, which has three tendons in each direction. One should note that the behavior of all the models is the same exactly and can see the effect of a pre-stressing force on the behavior of the slabs, the first cracking occur at the load, approximately 30-55 KN, The models also fails at a greater load than the specimen without pre-stressed. As the pre-stressing force is increasing the first crack, ultimate load, as well as the ductility increased. From the load-deflection curves, it seems that a pre-stressing force of $60 \mathrm{KN}$ is the optimum value to achieve a good approximation of the curve. 


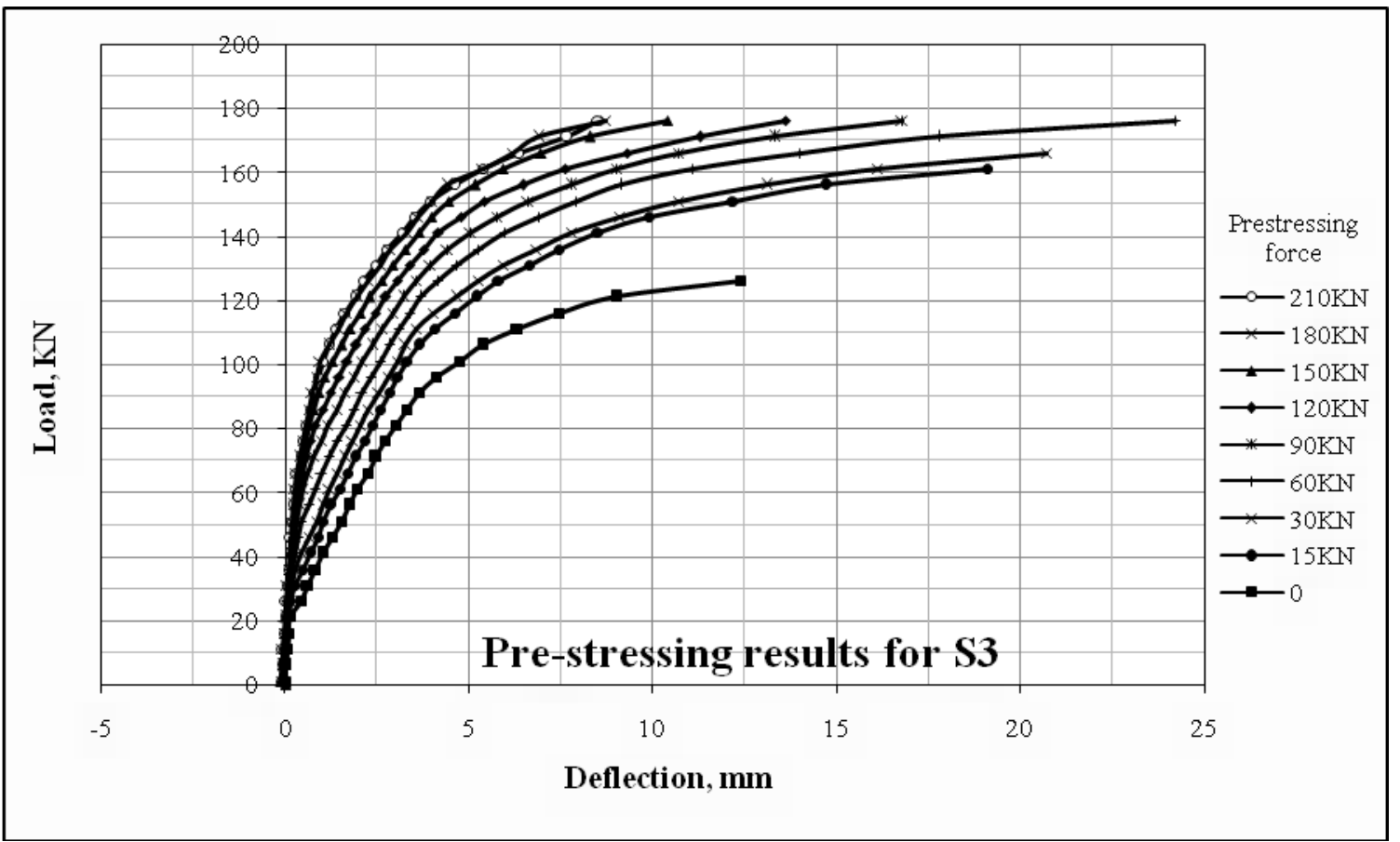

Fig (10): Load-deflection curves for three tendons slab

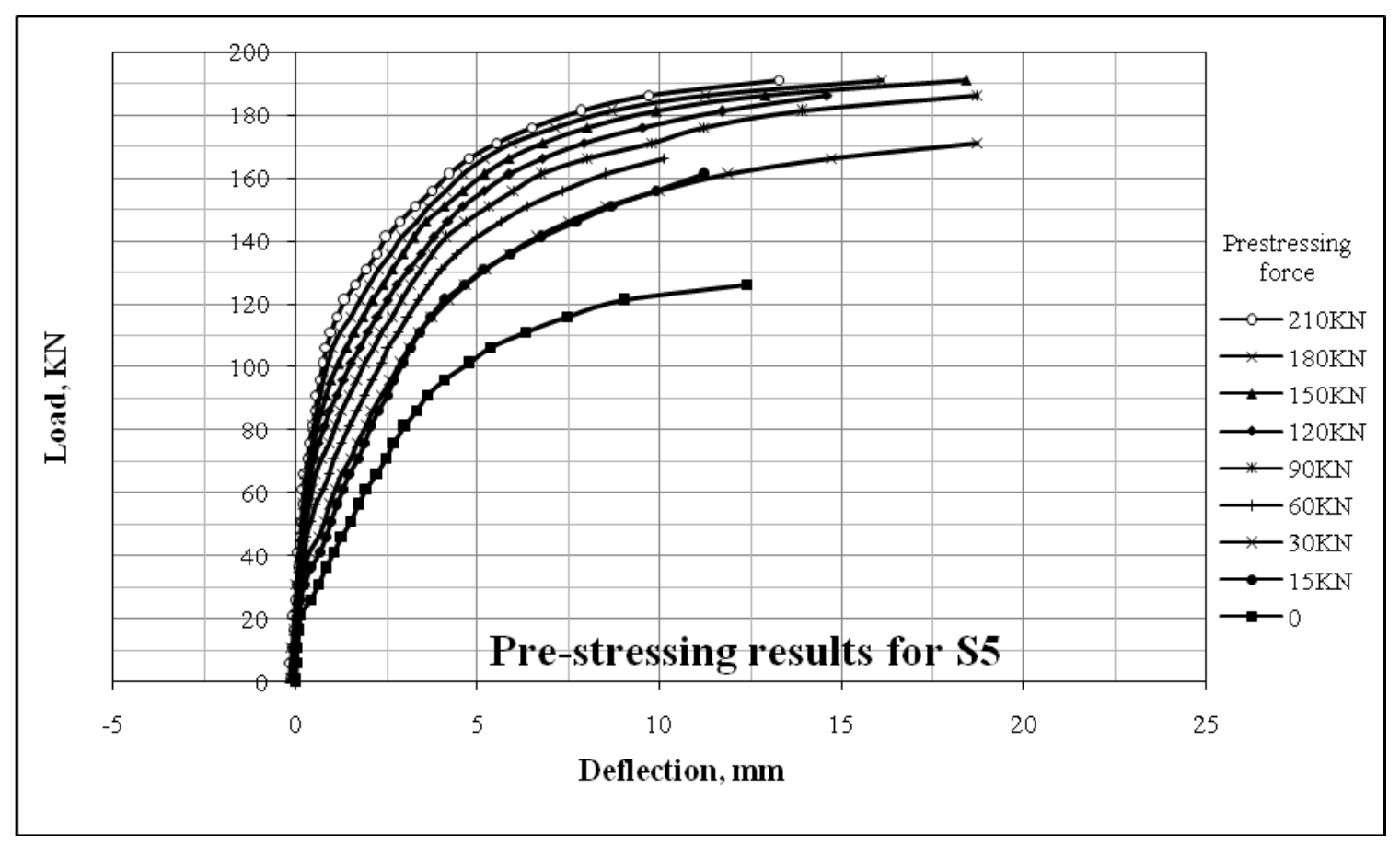

Fig (11): Load-deflection curves for five tendons slab

The second curves shown in Fig. 11, the first cracking of the numerical models slabs S5 occur at the load, approximately 30-60 KN. also one can see the effect of a pre-stressing 
force on the behavior of the slabs. The models also fails at a greater load than the specimen without pre-stressed. From the load-deflection curves it seems that, a prestressing force of $150 \mathrm{KN}$ is the optimum value to achieve a good approximation of the curve.

It noted that, by increasing the pre-stressing force, an increase of 30-40\% in punching shear capacity has achieved.

It can be concluded, that increasing the pre-stressing force load give more confinement for slabs, as well as more enhancement in behavior and the punching shear capacity.

Looking to the two curves shown in Figures $(10,11)$; one can see that there is a slight difference, with the bilinear plastic option giving the best result. The initial part of the curves is the same exactly before cracking occurrence. They follow approximately the same path until the model fails at a load. Therefore, decided to use the bilinear version of the stress-strain relationship for the rest of the models that were developed.

\subsection{Effect of numbers of tendons:}

The effect of spacing and number of tendons on the behavior of slab is shown in Fig. 12. Slab S3 that has three tendons with spacing between tendons $200 \mathrm{~mm}$ and $90 \mathrm{KN}$ of pre-stressing force in each direction achieved failure load of $175 \mathrm{KN}$, and the first cracking load of $40 \mathrm{KN}$.

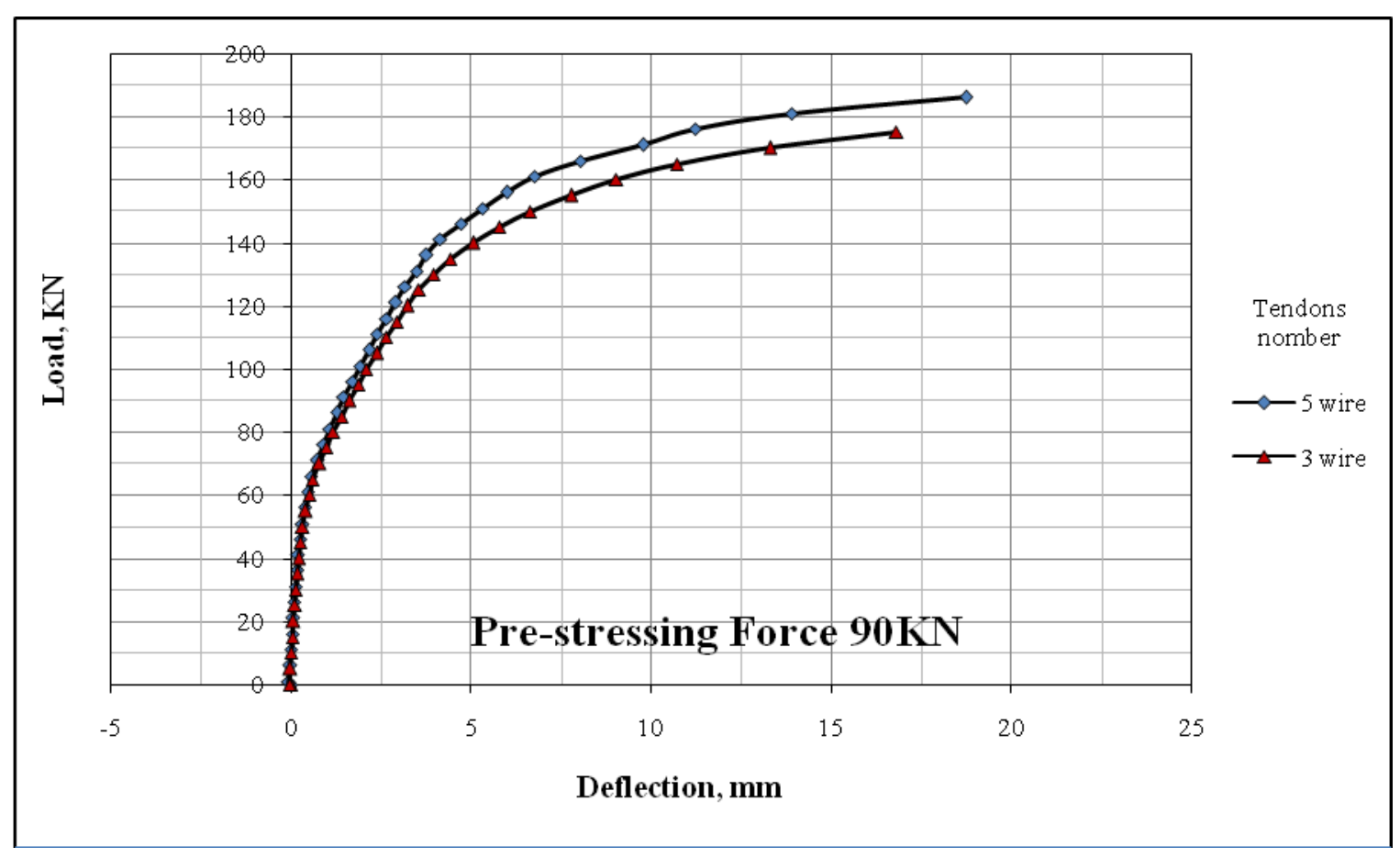

Fig (12): Load-deflection curves for 90KN of pre-stressing force 
While the slab S5 which have five tendons with spacing between tendons $100 \mathrm{~mm}$ and the similar of pre-stressing force in each direction achieved failure load of $185 \mathrm{KN}$, and the first cracking load of $45 \mathrm{KN}$.

Fig. 13 shows the relationship between tendons number, failure load and deflection at the $210 \mathrm{KN}$ pre-stressing force level. Slab S3 achieved failure load of $175 \mathrm{KN}$, and the first cracking load of $60 \mathrm{KN}$, while the slab S5 achieved failure load of $190 \mathrm{KN}$, and the first cracking load of $65 \mathrm{KN}$.

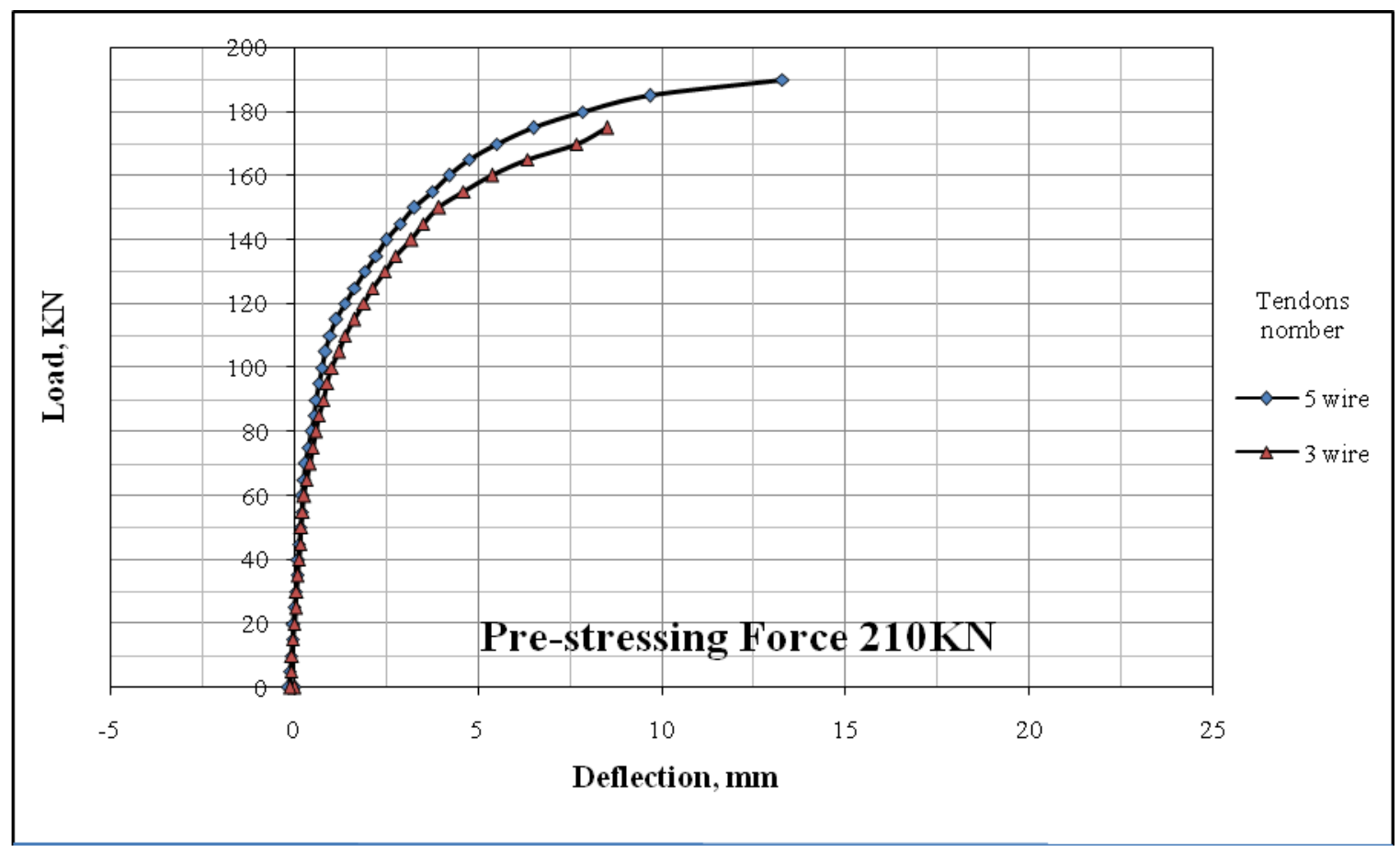

Fig (13): Load-deflection curves for 210KN of pre-stressing force

From Figures $(12,13)$ it is clear that the ductility of slabs S5 has the greater values.

It can be concluded that by increasing the number of tendons the failure and crack load increases and improve the general behavior of slabs.

\section{Conclusions:}

Based on the discussion of results obtained by numerical modeling, the following conclusions are extracted:

- The numerical investigations provide good agreement for the predicted results of the ultimate load, the cracking load, and the associated deflection.

- The general behavior and load capacity of flat slabs significantly influenced by pre-stressing. It is clearly noted that the failure load, cracking and ductility of prestressed slabs is generally greater than ordinary reinforced concrete slabs. 
- Increasing the pre-stressing force within the safety limits of stresses leads to more confinement for slabs, and more enhancements in behavior and punching shear capacity.

- Increasing the number of tendons with keeping some of tendons passing through the column in two directions increases the failure and cracking loads. As well as, improves the ductility that led to increasing of punching resistance.

\section{References:}

[1] Xiao RY, T. O'Flaherty. Finite-element analysis of tested concrete connections. Computers and Structures 78 (2000), pp: 247-255.

[2] ANSYS, User's Manual, vols. I-IV, Revision 5.1. Swanson Analysis Systems Inc, 1994.

[3] Gardner NJ, Shao X.Y. Punching shear of continuous flat reinforced concrete slabs. ACI Struct J. 1996; 93; pp: 216-28.

[4] Anthony J. Wolanski, B.S. Flexural Behavior of Reinforced and Pre-stressed Concrete Beams Using Finite Element Analysis. Thesis submitted. Milwaukee, Wisconsin. May 2004.

[5] P. Fanning, Nonlinear models of reinforced and post-tensioned concrete beams. Electronic journal of structural engineering, 2 (2001), received 20 Jul 2001; revised 8 sep 2001; accepted 12 sep 2001.

[6] Amer M. Ibrahim. Finite element modeling of continuous reinforced concrete beam with external pre-stressed. European Journal of Scientific Research ISSN 1450-216X. Vol.30, No.1, (2009), pp: 177-186. 